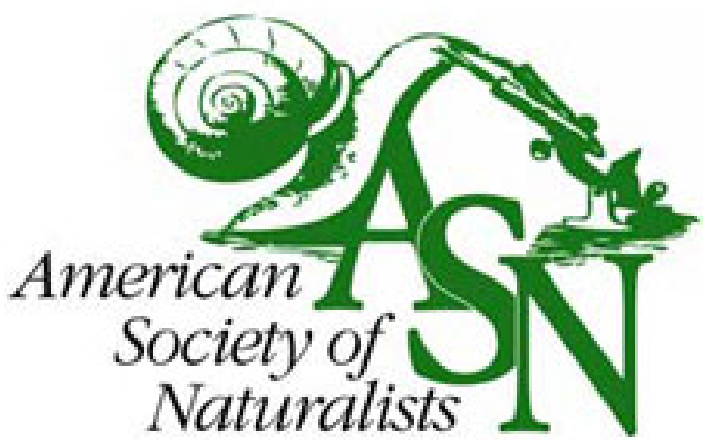

The University of Chicago

The Role of Despotism and Heritability in Determining Settlement Patterns in the Colonial Lesser Kestrel.

Author(s): David Serrano and José L. Tella

Reviewed work(s):

Source: The American Naturalist, Vol. 169, No. 2 (February 2007), pp. E53-E67

Published by: The University of Chicago Press for The American Society of Naturalists

Stable URL: http://www.jstor.org/stable/10.1086/510598

Accessed: 18/10/2012 06:18

Your use of the JSTOR archive indicates your acceptance of the Terms \& Conditions of Use, available at

http://www.jstor.org/page/info/about/policies/terms.jsp

JSTOR is a not-for-profit service that helps scholars, researchers, and students discover, use, and build upon a wide range of content in a trusted digital archive. We use information technology and tools to increase productivity and facilitate new forms of scholarship. For more information about JSTOR, please contact support@jstor.org. 


\title{
The Role of Despotism and Heritability in Determining Settlement Patterns in the Colonial Lesser Kestrel
}

\author{
David Serrano ${ }^{*}$ and José L. Tella ${ }^{\dagger}$
}

Department of Applied Biology, Estación Biológica de Doñana, Consejo Superior de Investigaciones Científicas, Pabellón del Perú, Avenida María Luisa s/n, 41013 Sevilla, Spain

Submitted January 17, 2006; Accepted July 17, 2006;

Electronically published December 20, 2006

\begin{abstract}
Avian colony size variation is an evolutionary puzzle in terms of unequal fitness payoffs. We used a long-term marked lesser kestrel (Falco naumanni) population, where individual fitness increases with colony size, to test whether subordinates are evicted despotically from the largest colonies. Yearlings were smaller and lighter, were more attacked than expected, and lost most disputes over nest holes with older birds. Agonistic interactions increased with colony size; consequently, most first breeders recruited in colonies smaller than those at which they first tried to settle. As expected when subordination is a transient state, birds dispersed to a larger colony as they got older even after breeding successfully. The population consequences of these behavioral processes were that the relative frequency of yearlings and first breeders decreased with colony size. At the same time, breeding colony size was repeatable within individuals, so we estimated the amount of heritable variation in this trait. Estimates of heritability derived from parent-offspring and fullsib analyses were consistently high $\left(h^{2}=0.53\right)$ when individuals reached asymptotic morphological values and presumably overcame subordinate transient states. Age-related dominance asymmetries masked resemblance among relatives in colony size, but both phenomena seem to coexist in this population and explain a considerable proportion of colony size variation.
\end{abstract}

Keywords: despotism, heritability, colony size, age structure, Falco naumanni.

Understanding the mechanisms influencing the abundance and distribution of animals in heterogeneous environments is one of the most fundamental topics in ecology. Fretwell and Lucas (1970) and Fretwell (1972) concep-

\footnotetext{
* Corresponding author; e-mail: serrano@ebd.csic.es.

† E-mail: tella@ebd.csic.es.

Am. Nat. 2007. Vol. 169, pp. E53-E67. (c) 2007 by The University of Chicago. 0003-0147/2007/16902-41559\$15.00. All rights reserved.
}

tualized two evolutionary models of habitat selection assuming negative density-dependent effects on average suitability to explain animal distribution among patches. As applied to breeding habitat selection, the ideal free distribution (IFD) model postulates that individuals are free to move among sites, with average fitness at equilibrium being equalized across habitats because individuals assort themselves in proportion to the availability of resources. Alternatively, the central idea of the ideal despotic distribution (IDD) model is that some individuals are able to monopolize the best habitats and despotically relegate others to lower-quality patches in which their fitness is lower (Brown 1969).

In birds, two lines of evidence suggest that some kind of preemption (sensu Pulliam and Danielson 1991) often shapes the establishment of breeding sites, with densitydependent, unequal competitor, and site-dependent theories of habitat selection being widely invoked to explain both the distribution of individuals in heterogeneous environments and the regulation of populations (O'Connor 1985; Rosenzweig 1991; Rodenhouse et al. 1997; McPeek et al. 2001; Morris 2003). First, experienced individuals occur more often in sites of higher suitability than do younger individuals (Newton 1992; Holmes et al. 1996), which has usually been interpreted in terms of despotism (e.g., Andrén 1990; Møller 1995; Petit and Petit 1996). Second, a number of studies has indicated that as population size and density increase, an increasing proportion of animals occupy suboptimal sites, leading to reduced mean population fitness (the buffer effect; see Ferrer and Donázar 1996; Chamberlain and Fuller 1999; Sergio and Newton 2003). However, most studies have only partially evaluated and tested critical assumptions and predictions of IDD models (Ens et al. 1995; Rendón et al. 2001). Moreover, approaches aimed at giving causal interpretations from observed distribution patterns at a landscape scale should be extremely cautious when several mechanisms (or processes) can be involved (e.g., Rosenzweig 1991; Lima and Zollner 1996; Clinchy et al. 2002; Carrete et al. 2006), so a better understanding of the importance of despotism in determining animal abundance and dis- 
tribution patterns can be achieved only by also studying the behavioral mechanisms underlying settlement across a habitat-quality gradient.

In social animals, the adaptive and ecological significance of individual distribution patterns in relation to group size is crucial in several respects and has long attracted the interest of ecologists. Particularly, the evolutionary and ecological basis of avian colony size selection continues to be elusive (e.g., Brown et al. 1990; SiegelCausey and Kharitonov 1990). Even in the cases in which average individual fitness has been found to vary with colony size, some individuals settle in suboptimal colonies, so colony size variability remains "one of the biggest enigmas associated with coloniality" (Brown and Brown 2001, p. 54). In this sense, it has been argued that some sort of constraint, such as competition over resources or density dependence, could prevent optimal habitat selection choices (e.g., Potts et al. 1980; Shields et al. 1988; Brown et al. 1990; Forbes and Kaiser 1994; Brown and Rannala 1995; Serrano et al. 2004), although there are no consistent data bridging the gap between the behavioral factors that determine settlement patterns and their influence on the size and demographic structure of colonies. Conversely, when fitness prospects do not vary among differently sized groups, variation in colony size has been proposed to be simply an emergent property arising from passive aggregations and individual dispersal decisions (Shields et al. 1988; Safran 2004). However, accumulating evidence suggests that heterogeneity in how particular individuals are affected by group size could drive group formation, variation, and structure (Brown et al. 1990; Krause and Ruxton 2002). In this sense, settlement decision rules used by animals could be genetically determined, as has been indicated for other behavioral traits (e.g., Drent et al. 2003; Maestripieri 2003). Studying the heritability of group size, in combination with studies of fitness payoffs in different social contexts, is thereby a fundamental step toward understanding its evolutionary dynamics and predicting evolutionary outcomes in specific selective scenarios. In particular, it has been recently suggested that colony size preferences may reflect heritable variation in the ability of individuals to cope with different social environments (Brown and Brown 2000; Møller 2002).

Elsewhere, we showed that both philopatry and immigration in lesser kestrels (Falco naumanni) were associated in a quadratic way with the number of previously settled conspecifics, suggesting not only that colony attractiveness increases with colony size but also that, beyond a threshold, recruits are faced with disproportionate settlement costs (Serrano et al. 2003, 2004). While these findings suggested colony regulation, the precise mechanisms causing negative density dependence in the largest colonies were unknown. In this article, we tested whether the distribution of individuals across colony sizes resulted from despotism and/or from an intrinsic property to settle in different social environments. To do so, we used both an extensive data set of marked individuals to explore how first breeders distributed across colony sizes and detailed observations during the settlement period to investigate the behavioral mechanisms underlying distribution patterns. Detailed data on phenotypic resemblance among relatives are used to estimate the amount of heritable variation in breeding colony size of this facultatively colonial species.

\section{Assumptions and Predictions}

Lesser kestrels at the Ebro Valley (northeastern Spain) provided an excellent model to test the above-mentioned hypotheses. Colonies in the study population formed discretely patchy breeding habitats that varied in size from solitary pairs to colonies gathering up to approximately 40 breeding pairs (fig. 1). In addition, kestrels had a wide range of settlement options in terms of colony size at a natal dispersal scale (Serrano et al. 2004), so colony choice was not constrained by the availability of potential alternatives (Brown et al. 1990).

Owing to asynchronous settlement of individuals over the course of the breeding season, lesser kestrels should be able to predict final colony size at any time of the settlement period. The number of birds detected in periodic censuses from the arrival of the first individuals to mean laying date was strongly correlated to final colony size (Serrano et al. 2004). Thus, this assumption is fulfilled in our population. On the other hand, critical assumptions behind Fretwell-Lucas models should be met first if any kind of ideal distribution is involved. First, colonies should differ in intrinsic quality (Ens et al. 1995; Petit and Petit 1996). In our study population, predation risk decreased with colony size mainly because large colonies persisted in predator-free sites but also because of increased antipredator efficiency with group size (Tella 1996; Serrano et al. 2004). As a result, both breeding success and adult survival increased with colony size (Tella 1996; Serrano et al. 2005a), and so colony size selection deviates from an IFD model. Second, individuals should be able to judge habitat quality. Lesser kestrels discerned colony quality according to the presence and number of previously settled conspecifics. Birds mainly settled in previously occupied buildings (88\%; Serrano et al. 2003), and rates of natal and breeding philopatry increased with colony and local population size (Serrano et al. 2001, 2003; Serrano and Tella 2003). Moreover, colony attractiveness for both firstbreeding and adult immigrants increased with colony size (Serrano et al. 2004). Nonetheless, both natal philopatry and immigration rates were predicted by the number of 


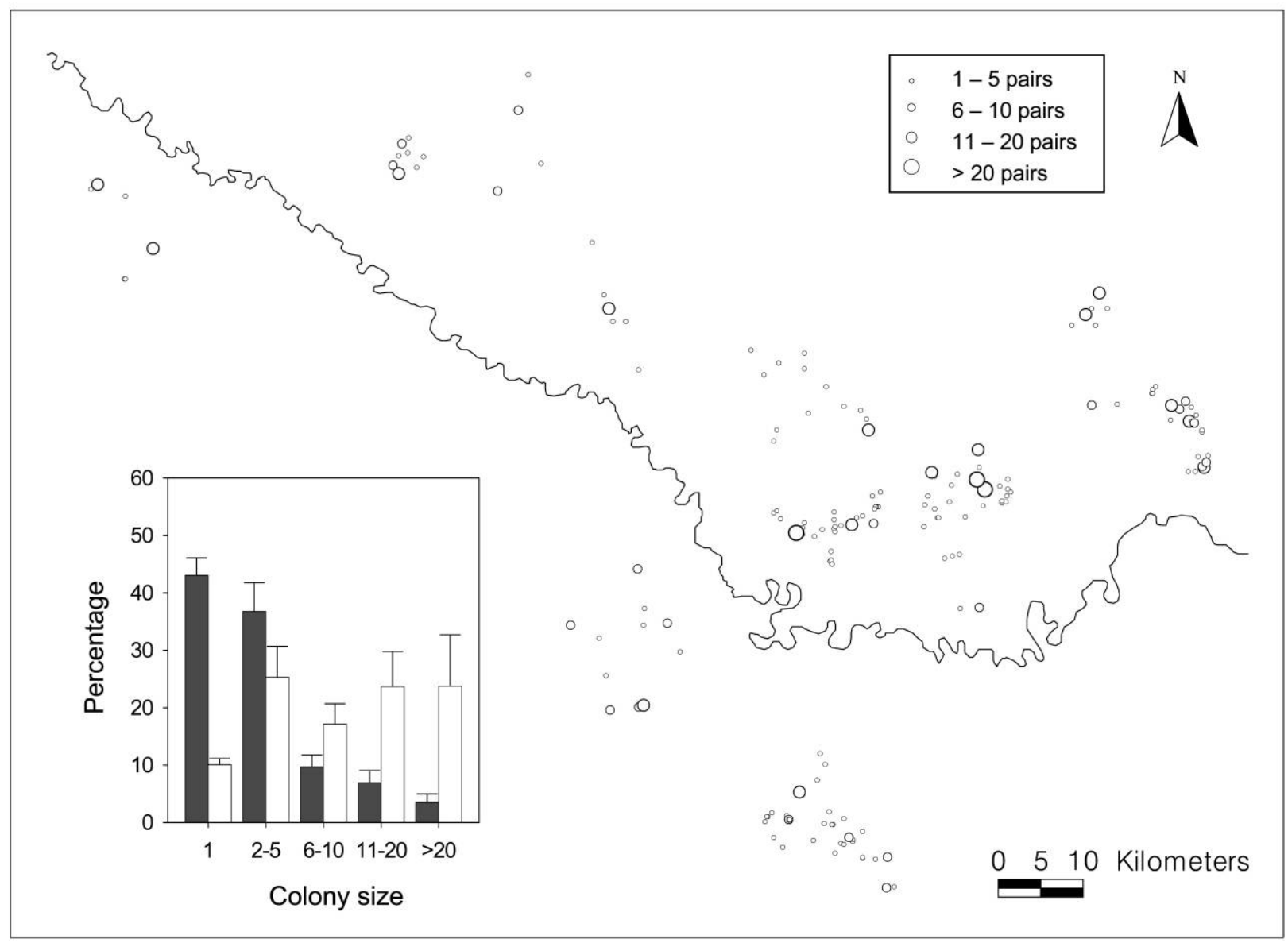

Figure 1: Map of the Ebro Valley showing the Ebro River and the spatial distribution of differently sized colonies in the last year of study (2000). Inset, mean \pm SD percentage of colonies (filled bars) and percentage of individuals (open bars) breeding in colonies of different size during the study period (1993-2000).

philopatric adults in a quadratic fashion, indicating that a relatively lower proportion of newcomers settled in the largest colonies (Serrano et al. 2003, 2004).

One prediction of the IDD hypothesis is that individuals settling in the best colonies should be of higher phenotypic quality than individuals settling in suboptimal sites (Petit and Petit 1996), although even if specific patterns of settlement vary as predicted, this does not necessarily imply despotism. To demonstrate despotism, one should show that subordinates breeding in a low-quality habitat had first attempted to settle in a better habitat from which they were evicted by dominants. We first tested whether individual quality was at least in part a dynamic characteristic that increased with age and experience (e.g., Komers 1989; Sherry and Holmes 1989; Post 1992; Poston 1997; Donázar et al. 1999). We then expected (i) yearlings to lose territorial conflicts with older conspecifics, (ii) first-breeding birds observed in two different sites during the same breeding season to finally breed in smaller colonies than those in which they first tried to settle, and (iii) individuals to choose to settle in better habitats, that is, larger colonies, as they get older and gain competitive skills (Heg et al. 2000; Rodenhouse et al. 2003).

\section{Methods}

\section{Study Species and Study Area}

The lesser kestrel is a small-sized, long-distance migratory and insectivorous falcon. It has a sexually dimorphic plumage, making the sexes easily distinguishable in the field. First-year males show a transition plumage between fledgling and adult, but female ages are difficult to determine (Negro 1997). In the study area, first-arriving individuals settle in the colonies in late February and leave them in August. The first yearlings arrive about 1 month later than 
first adults, and most individuals breed for the first time in their first or second year of life. At arrival, males choose a nest hole and vigorously defend a small area around it while displaying to attract females, but they are otherwise nonterritorial. Once paired, females also defend the nest hole and its surroundings. Males and females also share parental duties and are mostly monogamous (Alcaide et al. 2005)

Lesser kestrels were studied from 1993 to 2000 in a large geographic area $\left(10,000 \mathrm{~km}^{2}\right.$; Ebro Valley, northeastern Spain). There, they bred primarily in holes under tiled roofs of abandoned farmhouses surrounded by extensive cultivations of cereals (Tella et al. 1998). Buildings were occupied by both solitary pairs and colonies of two to 43 pairs (fig. 1). Our study population increased from 224 pairs in 1993 to 787 pairs in 2000, but frequency distributions of colony sizes did not change substantially over the years (Serrano et al. 2005a). Although some buildings were colonized each year, $90.8 \%$ of apparently suitable buildings (in terms of breeding cavities and foraging grounds) remained unoccupied in the final year of this study.

\section{Population Monitoring}

From 1993 to 1999 , 4,901 fledglings and 640 adults were banded with a metal and a plastic band engraved with a unique alphanumeric code that could be read at distance with telescopes. Each year, regular surveys were carried out to locate colonies and to read bands. Intensive observations of banded kestrels were made mostly during the prelaying period (from March to middle May), when we tried to determine the identity of all birds present at the colonies. We assigned individuals to established or nonestablished status by means of behavior: established birds consistently defended a breeding cavity and were involved in copulation and mate-feeding behaviors, whereas nonestablished birds were prospecting individuals looking for a vacant nest hole. Capture-recapture histories were completed from May to July each year when we surveyed the colonies directly to record breeding parameters. Colony size was defined as the final number of established pairs defending a nest site, that is, attempting to breed. Further details about field procedures can be found in work by Serrano and Tella (2003) and Serrano et al. (2004).

\section{Distribution of First Breeders, Phenotype, and Agonistic Interactions}

In a scenario of age-related despotic distribution, we expected the proportion of young individuals to decrease with colony size (see Graves 1997; Rohwer 2004). Because a number of kestrels breeding for the first time when they were 1 year old could have been misclassified as 2-yearold first breeders, we also tested this hypothesis by using only the proportion of yearling first breeders. From these analyses, we excluded the largest colony of the population because it was on a structurally complex building and its growth was due to the simultaneous occupation of an empty sector. Thus, its size did not reflect individual density, and agonistic interactions were not comparable with the rest of the colonies.

We also studied whether individuals of different age differed in their phenotypic traits by analyzing differences in size and body mass, considering six age classes. Wing length was used as the best estimator of body size in this species (Tella 1996). Body mass was analyzed separately for males and females because time elapsed after laying the first egg must be included as a covariate in the models to account for female body mass loss along incubation (Serrano et al. 2005b).

In 1994, detailed observations were made from arrival to laying date (i.e., during the settlement period, from late February to middle May) at 14 buildings that held a variable number of breeding pairs (from one to 33), using telescopes at distances that did not interfere with the behavior of birds. Observations were conducted avoiding rain, extremely windy days, and the central hours of the day (when kestrel activity is minimized). A total of $961 \mathrm{~h}$ of observation were evenly distributed among colonies and along the settlement period, recording 982 aggressive encounters between birds. Whenever possible, the identity of the individuals, their sex and age (yearlings or adults, in the case of males), and the outcome of the interactions were noted.

In the 7 years of study, a number of first-breeding individuals were observed during the same breeding season trying to settle in two different colonies. These data allow testing whether birds initially tried to settle in a better colony than that in which they finally bred.

\section{Repeatability in Colony Size and Resemblance among Relatives}

To ensure that resemblance among relatives in colony size was not trivially explained by philopatry, we analyzed data from birds that emigrated from their natal colony (Brown and Brown 2000). To examine whether individuals consistently settled for breeding in colonies of similar size throughout their lives, we used the intraclass correlation coefficient (Lessells and Boag 1987). Breeding colony size for each bird (parent or offspring) was obtained after averaging all colony sizes in which it was known to breed. Heritability $\left(h^{2}\right)$ estimates were obtained from the slope of a weighted regression of midoffspring on midparental and from twice the slope of midoffspring on single-parent 
weighted regression (Falconer and Mackay 1996). Regressions were weighted by the number of colonies used to estimate midoffspring colony size. An alternative heritability estimate was derived from a full-sib ANOVA with nest identity as a factor and calculated as twice the intraclass correlation coefficient (Falconer and Mackay 1996). Standard errors were calculated following Becker (1984). Both parent-offspring regressions and full-sib analyses may underestimate heritabilities if individuals attending the nests are not the genetic parents of all or part of the offspring. This is not likely to occur in our studied system because extrapair fertilizations and brood parasitism are infrequent (7.25\%; see Alcaide et al. 2005).

\section{Statistical Analyses}

Most analyses were performed within a generalized linear model framework via maximum likelihood techniques (McCullagh and Nelder 1983). Multiple logistic regression analyses were used for binary dependent variables (PROC GENMOD in SAS with binomial distribution of errors and logistic link function), and ANOVAs and ANCOVAs for normally distributed data (PROC GENMOD with normal distribution of errors and identity link function). Variancecovariance structures were modeled with generalized linear mixed models (GLMMs) when individuals were obtained from repeated observations of the same colonies across different years. Appropriate distributions of errors and link functions were implemented in the GLIMMIX SAS macro (Littell et al. 1996). In these mixed models, colony identity and year were fitted as random terms to account for nonindependence of observations and between-year stochasticity. Individual identity was also fitted as a random effect when there were several measurements of the same individuals over time. For analyzing the proportions of both total and yearling first breeders per colony, we used the total number of individuals as a binomial denominator in order not to lose information about sample size (Crawley 1993). Significance was based on F-tests. Other, simpler analyses were done using nonparametric tests (Wilcoxon matched paired tests, Spearman correlation, $\chi^{2}$, and test of proportions). All tests were two-tailed except for directional predictions. All analyses were performed in SAS, version 8.0, and SPSS, version 13.0.

\section{Results}

\section{Distribution of First Breeders across Colony Sizes}

The proportion of first breeders decreased with colony size while controlling for site and year effects, both when the whole data set and when only the first breeding yearlings were considered (table 1; fig. 2). Colony size entered in a
Table 1: Mixed binomial model for the effect of colony size and sex on the proportion of first-breeding and yearling lesser kestrels in the Ebro Valley

\begin{tabular}{|c|c|c|c|c|}
\hline Parameter & Estimate & SE & $F$ & $P$ \\
\hline \multicolumn{5}{|l|}{ First breeders: ${ }^{a}$} \\
\hline Intercept & .451 & .180 & & \\
\hline Colony size & -.134 & .0225 & 34.6 & $<.0001$ \\
\hline$(\text { Colony size })^{\mathrm{b}}$ & .00294 & .00061 & 23.4 & $<.0001$ \\
\hline Sex (males) & .00939 & .131 & .01 & .94 \\
\hline Colony size $\times$ sex & .00663 & .00852 & .6 & .44 \\
\hline \multicolumn{5}{|l|}{ Yearlings: ${ }^{c}$} \\
\hline Intercept & -.104 & .246 & & \\
\hline Colony size & -.140 & .0222 & 37.4 & $<.0001$ \\
\hline$(\text { Colony size })^{\mathrm{b}}$ & .00257 & .00055 & 22.0 & $<.0001$ \\
\hline Sex (males) & -.997 & .130 & 58.7 & $<.0001$ \\
\hline Colony size $\times$ sex & .0153 & .00912 & 2.8 & .09 \\
\hline
\end{tabular}

quadratic way in both models, indicating that the proportion of first breeders and yearlings strongly decreased from buildings with solitary pairs to medium-sized colonies and then remained relatively stable, or even increased, in the largest ones (fig. 2). In spite of this, an appreciable number of adults consistently bred solitarily or in small colonies (fig. 2). The sex effect in the mixed model of yearlings (table 1) is explained by the higher proportion of females that recruited as first-year breeders in the population (Serrano et al. 2003).

\section{Phenotype, Agonistic Interactions, and First-Breeding Colony Size}

We detected differences in wing length between the sexes and among age classes (mixed model with year, colony and individual nested within colony as random terms, age: $F=65.2, \mathrm{df}=5,137, \quad P<.0001 ;$ sex: $F=6.4, \mathrm{df}=$ $1,137, P=.012$; age $\times$ sex: $F=0.9, \mathrm{df}=5,132, P=$ .46; see fig. $3 A$ ). These differences were due to an increase in wing length between 1 and 3 years of age (CONTRAST statement, $F=232.9$, df $=1,137, P<.0001)$ but disappeared afterward (rest of comparisons: $F=0.5$, df $=$ $3,137, P=.68)$. After controlling statistically for age and sex effects, we did not detect any significant relationship between wing length and breeding colony size (colony size: $F=1.4, \mathrm{df}=1,130, P=.24$; colony size $\times$ age: $F=$ 0.4 , $\mathrm{df}=5,124, P=.84$; colony size $\times$ sex: $F=1.6$, $\mathrm{df}=1,124, P=.20$ ). Body mass of both males and females also varied with age (mixed model with year, colony and individual nested within colony as random terms, males: $F=5.2, \mathrm{df}=5,25, P=.0020$; females: time elapsed laying, $F=303.7$, df $=1,26, P<.0001$; body 

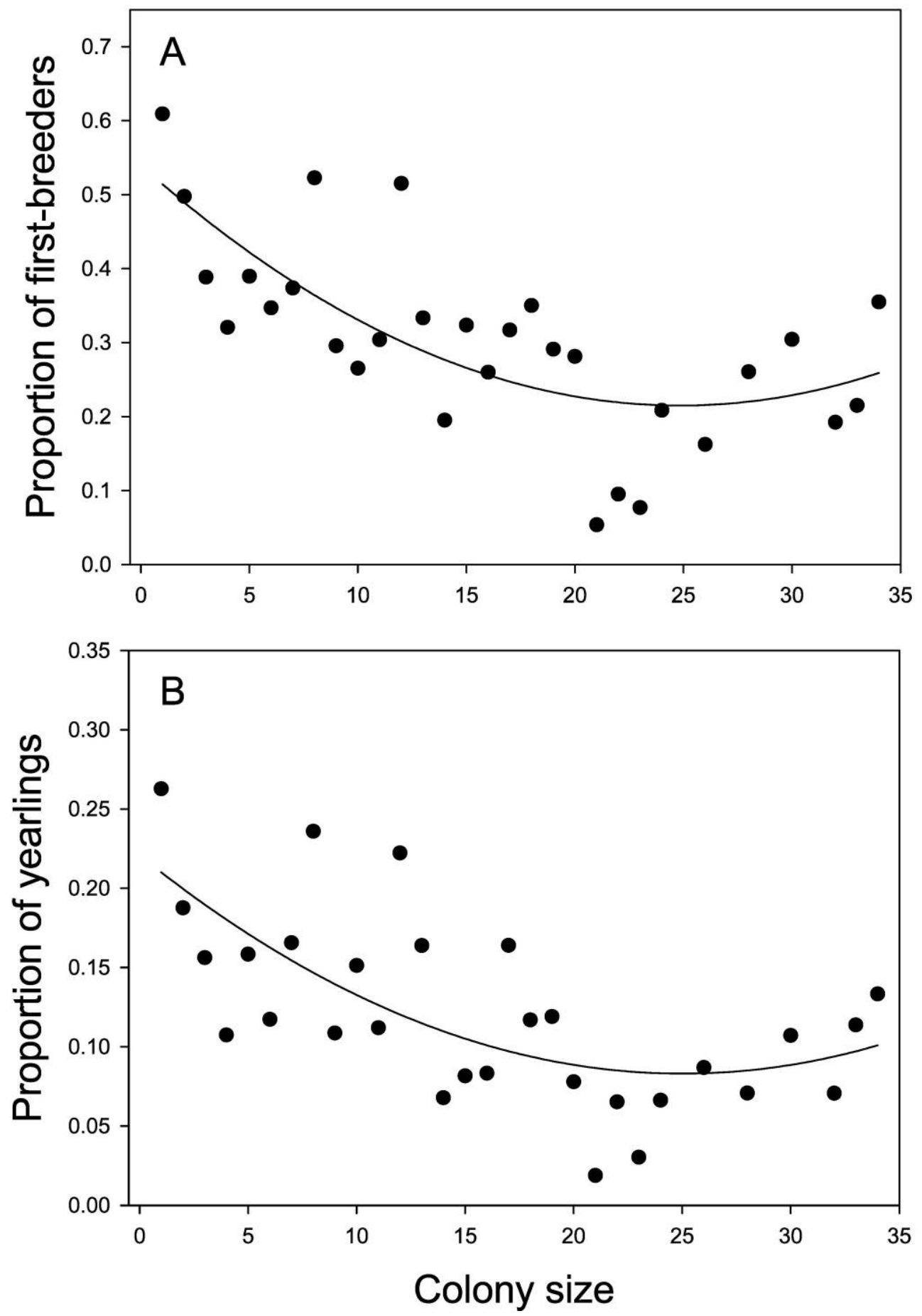

Figure 2: Proportion of all first breeders $(A)$ and yearling first breeders $(B)$ in relation to colony size at the Ebro Valley. Fitted lines are based on the parameter estimates from a binomial mixed model (see table 1 ). 


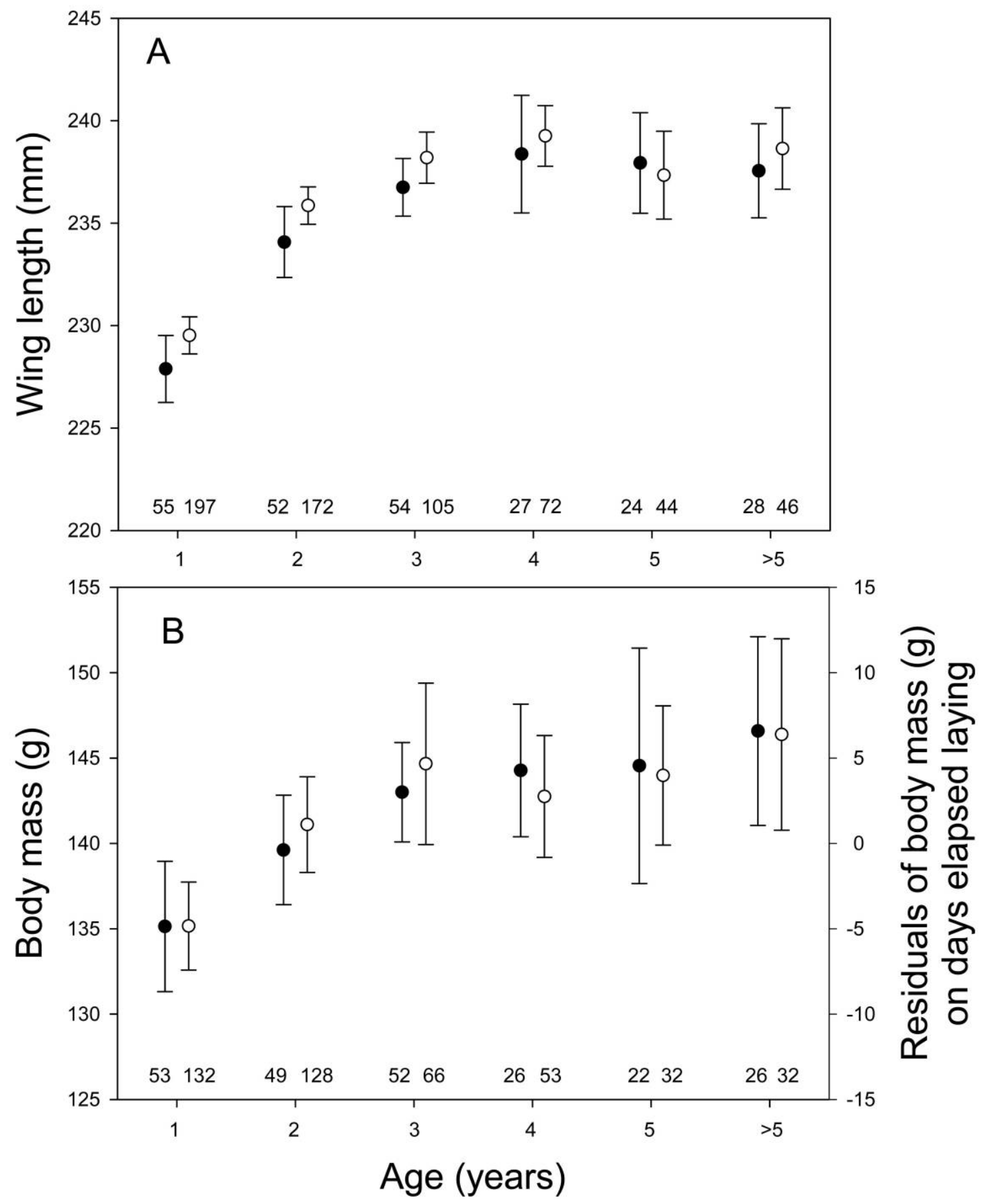

Figure 3: Wing length $(A)$ and body mass $(B)$ of males (open circles) and females (filled circles) in relation to age. Error bars are $\pm 95 \%$ confidence intervals (bootstrapped), and numbers above $X$-axis represent sample sizes. Note that residuals of body mass on days elapsed laying are represented in females to account for mass loss after laying.

mass, $F=8.8$, df $=5,26, P<.0001$ ). Body mass increased between the first and the third year of life in both sexes (males: $F=12.6$, df $=1,25, P=.002$; females: $F=27.0, \mathrm{df}=1,26, P<.0001)$ but not among older in- dividuals (males: $F=0.7$, $\mathrm{df}=3,25, P=.56$; females: $F=0.7$, df $=3,26, P=.58$; fig. $3 B$ ). Again, no relationship was found between body mass and breeding colony size after controlling for age effects in males (colony 
size: $F=1.6, \mathrm{df}=1,19, P=.22$; colony size $\times$ age: $F=0.9, \mathrm{df}=5,19, P=.49$ ) or in females (colony size: $F=0.7, \mathrm{df}=1,20, P=.43 ;$ colony size $\times$ age: $F=$ $1.0, \mathrm{df}=5,20, P=.41)$.

The frequency of agonistic interactions between birds defending a nest site increased with colony size $\left(r_{\mathrm{s}}=\right.$ $0.88, P<.001, N=14$; fig. 4$)$. Yearling males were attacked more than expected in relation to the relative frequency of yearling and adult breeders (Yates's corrected $\chi^{2}=17.6, P<.001, N=599$ aggressions; fig. 5). Moreover, yearlings lost the great majority of territorial conflicts when trying to gain access to a nest hole: $94.3 \%$ of encounters were lost when fighting with adult males $(N=$ 124 aggressions), and $94.7 \%$ were lost when fighting with females $(N=38$; test of proportions, $Z=9.9, \quad P<$ .0001 and $Z=5.5, P<.0001$, respectively). Consistent with these observations, first-breeding birds observed in two colonies during the same breeding season first tried to settle in larger colonies than those at which they finally bred (one-tailed Wilcoxon paired tests; mean \pm SE, males: $14.71 \pm 2.20$ vs. $6.64 \pm 1.63, \quad Z=-2.5, \quad P=.0065$, $N=28$; females: $13.06 \pm 2.02$ vs. $8.38 \pm 1.54, \mathrm{Z}=$ $-1.9, P=.026, N=34$; see fig. 6 ).

\section{Colony Size Selection after First Breeding Attempt}

Because high dispersal rates from small colonies were in part explained by the higher rates of nest predation at these sites (Serrano et al. 2001), we tried to isolate colony size from predation effects by analyzing only successful first-time breeders. For these birds, the probability of dispersing to another colony for their second breeding attempt was higher the smaller the breeding colony, both for males and females (binomial linear model, colony size: estimate $\pm \mathrm{SE}=-0.073 \pm 0.026, \quad \chi^{2}=9.0, \quad \mathrm{df}=1$, $P=.003 ; \quad$ sex: $\chi^{2}=0.6, \quad \mathrm{df}=1, \quad P=.46 ; \quad$ colony size $\times$ sex: $\chi^{2}=0.1$, df $=1, P=.79$ ). Furthermore, dispersing individuals tended to move to a larger colony for their second breeding attempt (one-tailed Wilcoxon test, males: $Z=-2.3, P=.01, N=52$; females: $Z=-2.5$, $P=.007, N=116$ ). These results did not change when only yearling first breeders were considered (one-tailed Wilcoxon test, males: $Z=-2.2, P=.01, N=23$; females: $Z=-2.3, P=.01, N=92$ ).

\section{Repeatability and Family Resemblance in Colony Size Selection}

In spite of phenotypic flexibility in breeding colony size, individuals tended to occupy colonies of similar size along their reproductive lives (intraclass correlation coefficient, $R=0.58, F=5.0, \mathrm{df}=971,1,833, P<.0001)$. After removing from the data set all individuals exhibiting natal philopatry, the weighted regression of midoffspring colony size on that of their parents yielded a low but significant estimate of heritability $\left(h^{2}=0.10 \pm 0.04, \quad F=7.9\right.$, $\mathrm{df}=1,621, \quad P=.005)$. The full-sib analysis showed higher but still low levels of heritability $\left(h^{2}=0.26 \pm\right.$ $0.16, F=1.3, \mathrm{df}=150,174, P=.035)$.

Because subordination is at least in part a transient state and individuals did not achieve asymptotic values in wing length and body mass until 3 years old, we restricted the heritability analyses to colony sizes where birds settled from this age onward, assuming that at this time most of them had occupied a colony size close to the preferred one. The heritability estimate obtained from midparent versus midoffspring regression with this subsample was about five times higher $\left(h^{2}=0.53 \pm 0.16, F=11.9\right.$, $\mathrm{df}=1,57, P=.001$; fig. 7$)$. The heritability estimate derived from the resemblances among full sibs was the same but with a larger SE $\left(h^{2}=0.53 \pm 0.32, F=1.6, \mathrm{df}=\right.$ 40, 43, $P=.06$ )

Heritabilities estimated by regressing midoffspring colony sizes against those of the father and the mother separately, using individuals $\geq 3$ years old, showed higher values for the father (father: $h^{2}=0.57 \pm 0.22, F=6.9$, $\mathrm{df}=1,80, P=.01$; mother: $h^{2}=0.47 \pm 0.19, F=6.0$, $\mathrm{df}=1,113, P=.02$ ), suggesting that maternal effects were not likely to be the major cause of parent-offspring resemblance in social propensity. We also tested whether this result could be explained by cultural transmission of the social environment (i.e., by social perception during the rearing stage), but the slope of the regression of midoffspring colony size (when $\geq 3$ years old) against natal colony size was not significantly different from $0\left(h^{2}=\right.$ $0.03 \pm 0.07, F=0.2, \mathrm{df}=1,153, P=.64$ ).

\section{Discussion}

Our study shows that colony size selection in lesser kestrels was a conditional strategy that depended on individual age at the same time that individual settlement in a particular group size exhibited considerable heritability. Despotic behaviors masked resemblance among relatives in their degree of sociality, which became more evident when site selection behaviors were not constrained by transient subordination states. The coexistence of both mechanisms explains why the proportion of first breeders was higher in small colonies while adults monopolized the large ones and also provides a potential explanation as to why a number of adults consistently bred solitarily or in small colonies.

A primary prediction of IDD models, that high-quality individuals should settle in the best habitats and lowerquality individuals in substandard sites, was strongly supported in our study system. Lesser kestrels obtain fitness 


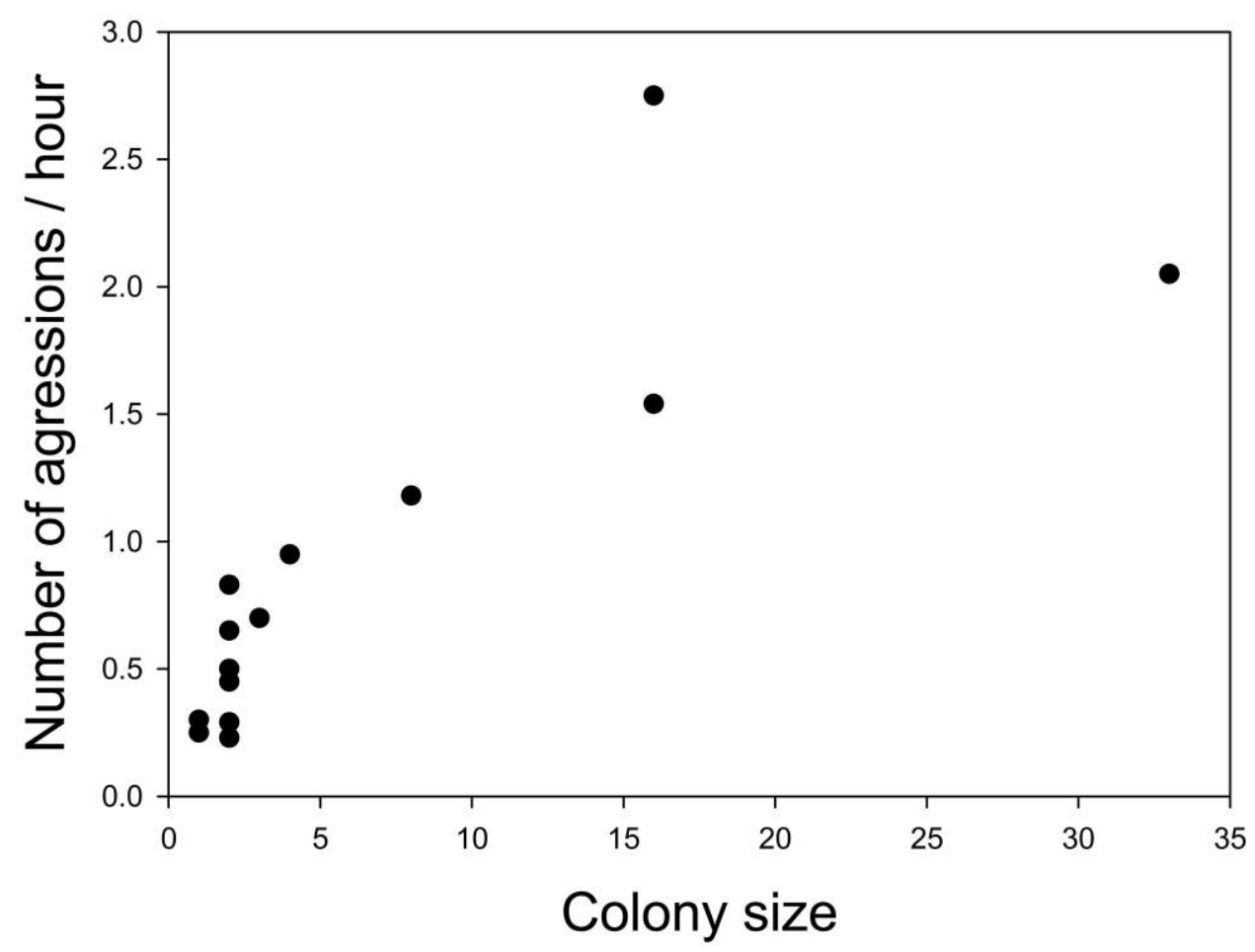

Figure 4: Frequency of aggressions in relation to the size of the 14 colonies studied during the settlement period.

benefits by settling in a large colony (Tella 1996; Serrano et al. 2005a) mainly because large colonies persist only in predator-free sites, and thereby conspecific attraction is a reliable habitat selection cue to individuals who lack experience at a site (Serrano et al. 2004). However, the frequency of aggressions also increased with colony size, thus creating a more hostile environment where newly arriving birds will find it more difficult to get and defend a nest site among previously settled ones. We have found that both males and females have deferred maturity in external size and body mass, not reaching asymptotic values until 3 years old, and this fact might reduce their chances of obtaining a nest hole when fighting with older, larger birds. Accordingly, detailed observations in the colonies indicated that violent agonistic interactions, which suppose a true risk of injury and considerable investments of time and energy (Tella 1996; D. Serrano and J. L. Tella, unpublished data), were disproportionately directed toward yearling males (the only sex age class distinguishable visually) and that they lost most aggressive encounters with older breeders when trying to settle in a colony and get a nest hole. Consequently, most first breeders finally bred in a smaller colony than the one at which they first tried to settle, indicating that they were not free to occupy the colony size of their choice and that older birds interfered with their habitat selection preferences and relegated them to suboptimal colonies. It remains to be elucidated, however, whether body mass and size directly determined the probability of winning territorial conflicts (the resource holding power of individuals; Parker 1974) or whether they operated indirectly via an effect on arrival date and priority access to high-quality colonies (Dittmann and Becker 2003; Ninni et al. 2004; Serrano et al. 2004).

Another important prediction of IDD models when subordination is a transient state is that birds should select a better habitat whenever possible (Ens et al. 1995; Heg et al. 2000). After their first breeding attempt, lesser kestrels are known to rely both on their breeding experience and on conspecific attraction to make their dispersal decisions (Serrano et al. 2001). Our results support the idea that the high propensity of first breeders to emigrate from small colonies was to a great extent irrespective of personal information about breeding success. Moreover, they tended to disperse to a larger colony, which might indicate that many birds preferred to rely on an indirect cue provided by conspecifics rather than their own personal information about patch quality. This strategy could be adaptive when there is low temporal autocorrelation in site quality (McPeek and Holt 1992; Switzer 1993), as seems to be the case for many small lesser kestrel colonies, but might also 


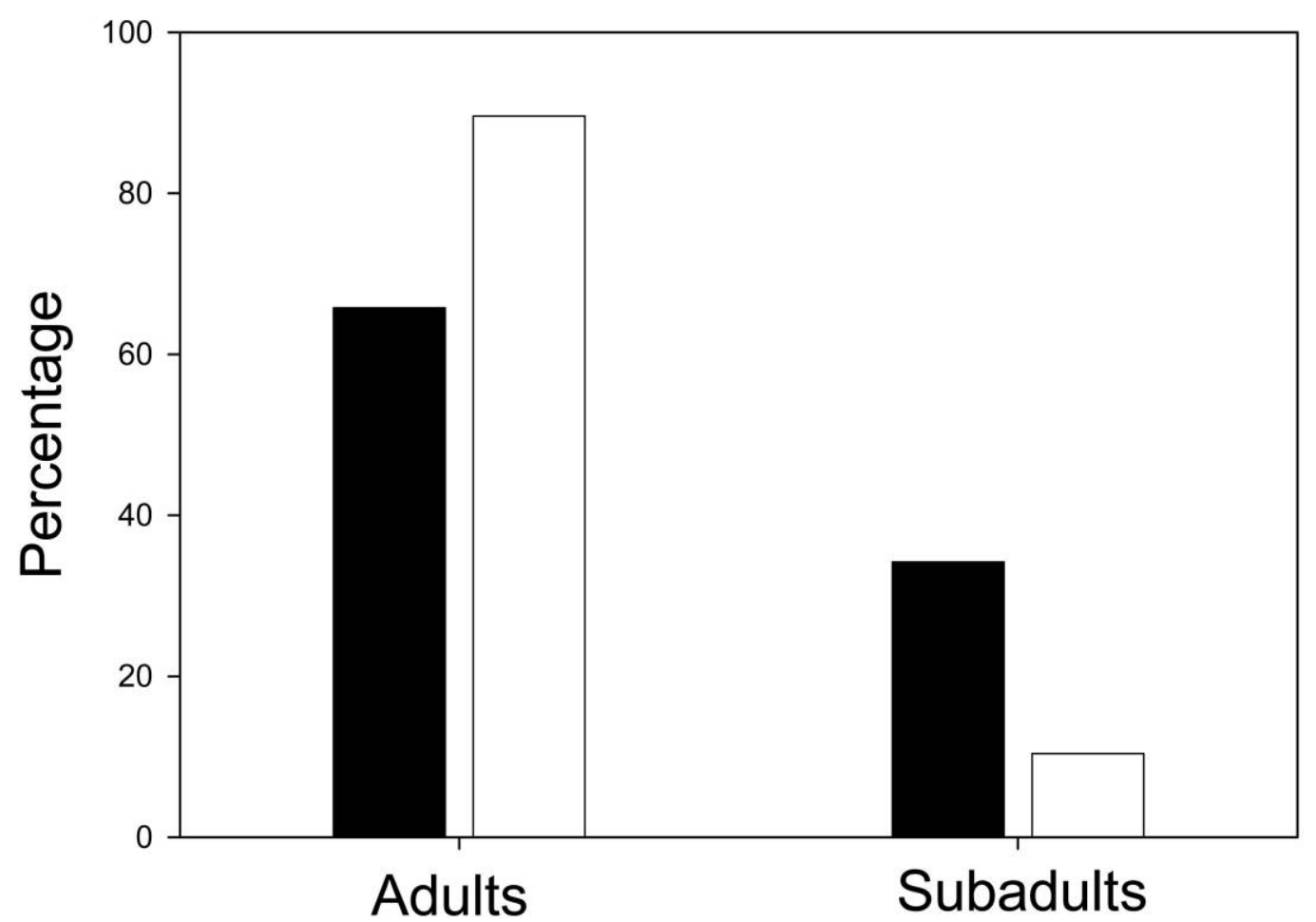

Figure 5: Percentage of aggressions $(N=514)$ addressed to adult and yearling lesser kestrel males ( filled bars) in relation to the relative abundance of these age classes $(N=85$ males, open bars $)$ in the 14 colonies where nest defense behavior was recorded during the settlement period.

reflect the propensity of individuals to disperse to a social environment to which they were more suited.

Using cross-fostering experiments, Brown and Brown (2000) and Møller (2002) showed the first evidence for a strong genetic basis of colony size selection in two species of swallows. In lesser kestrels, parent-offspring regressions and full-sib analyses initially suggested a relatively low heritable component in degree of sociality. This was not surprising because the heritability of a trait is assumed to be negatively related to its contribution to fitness (e.g., Merilä and Sheldon 2000). However, when we analyzed a restricted subsample of aged individuals that had reached relatively stable masses and sizes, estimates derived from both parent-offspring regressions and full-sib analyses were high and consistent $\left(h^{2}=0.53\right)$, revealing a close correspondence among the behavioral phenotypes of relatives. This finding could be explained, as previously suggested, by individual variation in social predisposition (Brown and Brown 2000), but it is also compatible with other interpretations. For example, if competitive ability is heritable, resemblance between relatives in colony size could simply reflect the fact that higher-quality individuals are more successful at competing for access to nest sites at large colonies. Moreover, if phenotypic quality predicts both parental care and breeding colony size, subsequent settlement patterns of the offspring could be explained by their condition, and genetic transmission could be minimal. Although we have not detected any association between breeding colony size and two relevant phenotypic traits such as mass and size, it is unclear the degree to which individuals could differ in other aspects of the phenotype that are less apparent. Only the fact that most adults breeding solitarily or in small colonies settled even several weeks before the largest colonies were saturated (Tella 1996) suggests that these birds were spontaneously choosing their social context rather than being displaced by dominant individuals, but the causal mechanisms explaining this pattern are difficult to unravel with correlational data. It is worth noting, however, that even with crossfostering experiments, it is not easy to isolate genetic from early maternal effects potentially linked to competitive abilities, such as steroid hormones transmitted into eggs (e.g., Schwabl 1996).

Irrespective of the causal mechanism, one key question from an adaptive perspective (if colony size in lesser kestrels is heritable) is how the coexistence of different behavioral strategies could be produced and maintained. In the Ebro Valley, predation should have caused directional 

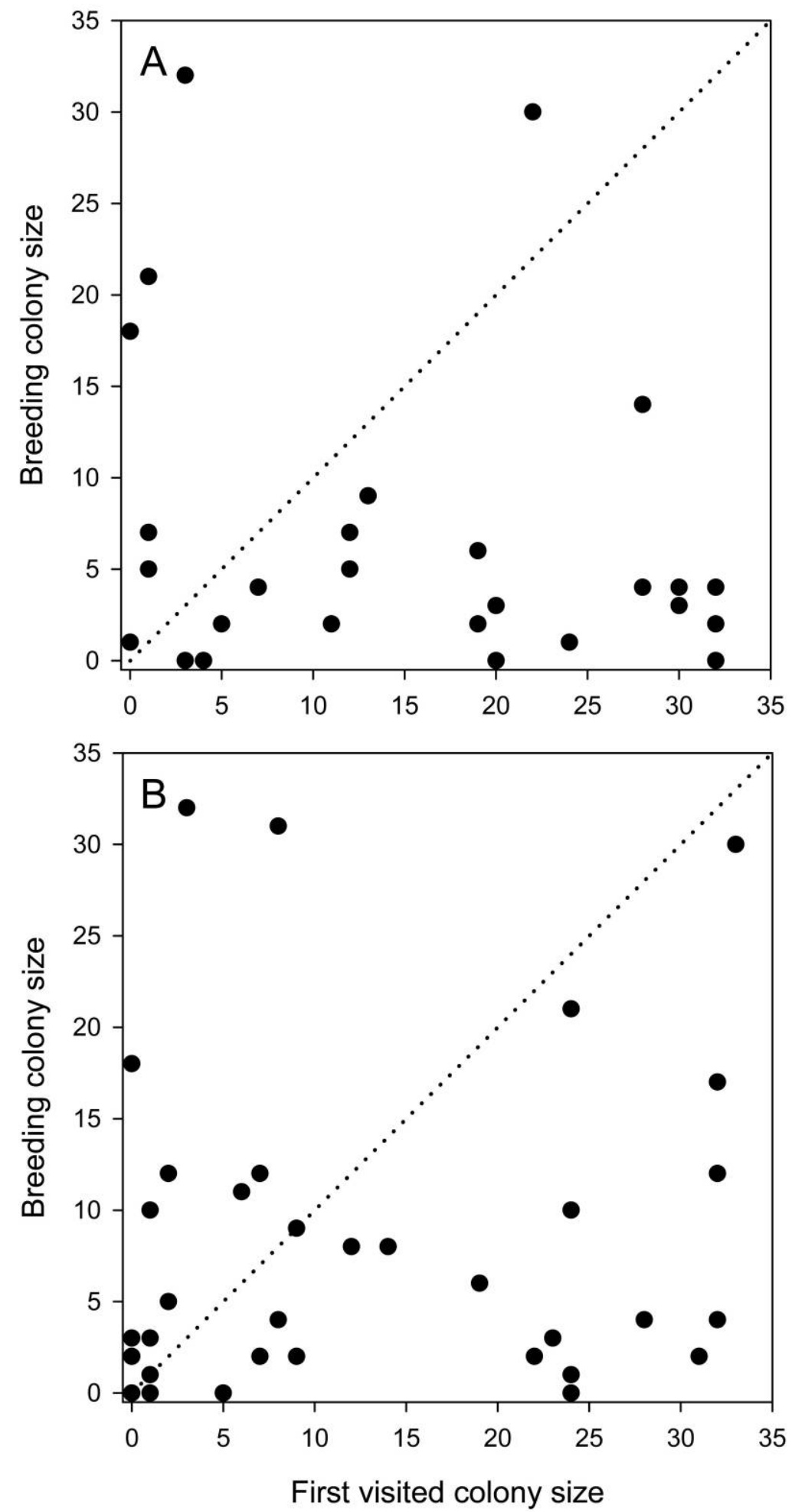

Figure 6: First visited and breeding colony size of first-breeding males $(A)$ and females $(B)$ observed in two different colonies during the same breeding season. Note that colony sizes do not include the target individuals and that in no case did members of the same breeding pair contribute to both the male and female data sets. Dots below the line correspond to individuals finally breeding in colonies smaller than those in which they initially attempted to settle in. 


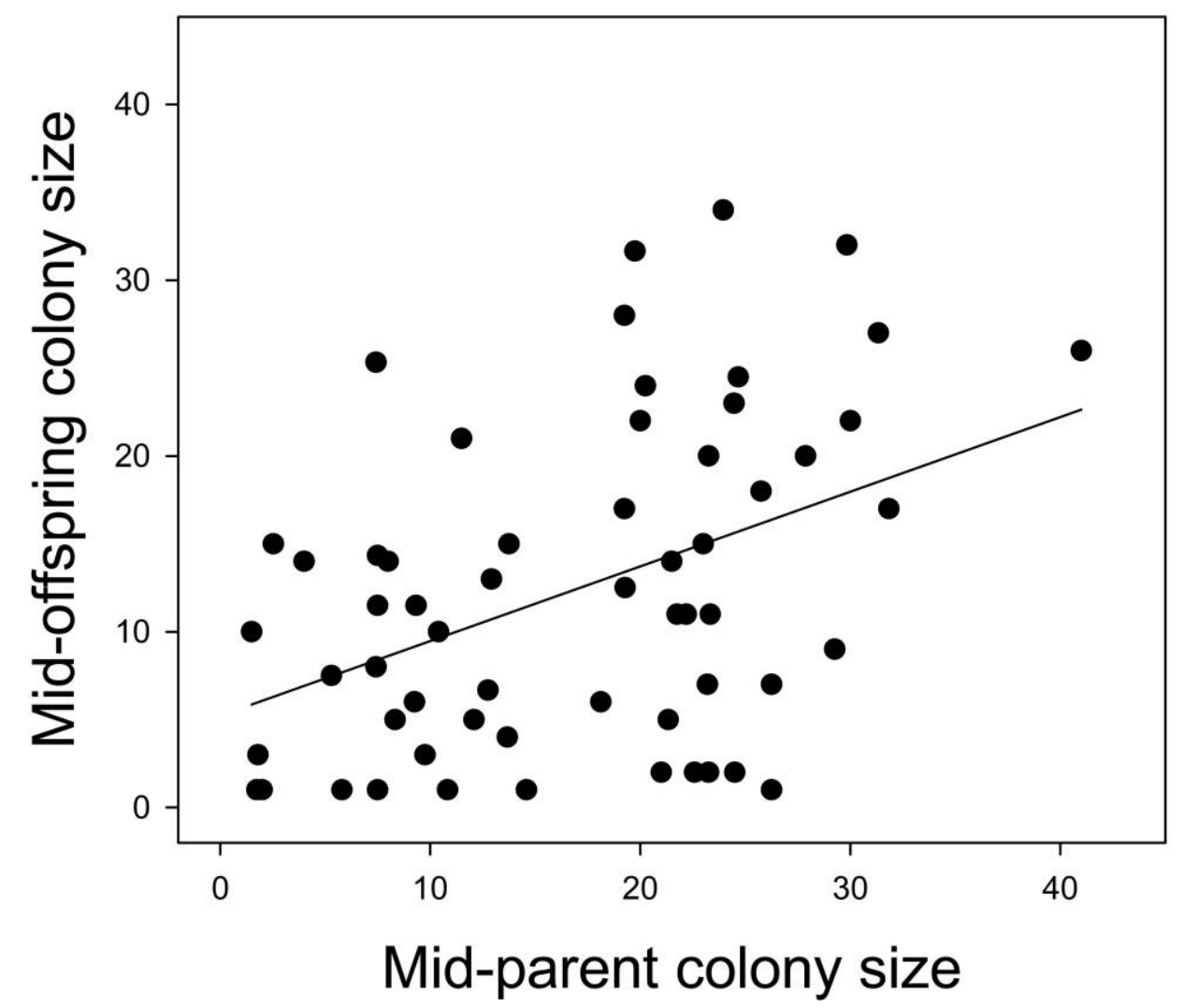

Figure 7: Midoffspring colony size regressed on midparent colony size for individuals $\geq 3$ years old.

selection against phenotypes breeding in small colonies, thus depleting genetic additive variance instead of maintaining the observed variation in colony size (Merilä and Sheldon 2000; Stirling et al. 2002). However, directional selection will result in observable changes only if it is consistent in space and time (e.g., Roff 1997; Merilä et al. 2001). With respect to space, other populations of lesser kestrels are known to experience much lower predation pressure (Tella et al. 1996), or the community of predators and its interaction with colony size is different (Tella et al. 2004). Although emigration from our population seems negligible (Serrano et al. 2001, 2003), immigration from some of these "low-predated" populations could provide alleles for lower social predispositions, preventing local adaptation and maintaining genetic variation in colony size (e.g., Postma and van Noordwijk 2005). In addition, temporal oscillations in colony size-specific selection pressures may favor different genotypes at different times, with the net result being that variation is maintained in the population (Roff 1997). For example, predation pressure usually decreases with colony size, but in some years, medium-sized colonies were more predated than smaller or larger ones (Serrano et al. 2005a).
Overall, our findings shed light on the factors affecting colony size variation in birds. Competition for breeding sites and subsequent dispersal behaviors may have important implications for the demography and the regulation of populations (Newton 1992; Rodenhouse et al. 1997; Kokko et al. 2004). In this way, despotism has been suggested to explain variation in group size (Potts et al. 1980; Shields et al. 1988; Brown et al. 1990; Forbes and Kaiser 1994; Brown and Rannala 1995), although good empirical evidence is so far scarce and indirect, even for territorial species of birds. One evident consequence of this study is that despotism regulates colony size, explaining why predator-free colonies remain relatively stable in size over the years (Serrano et al. 2004). As many individuals are obligated to make nonoptimal choices, despotism may also explain colony size variation at a regional level. More surprising is the fact that breeding colony size could be genetically determined (see also Brown and Brown 2000; Møller 2002). This finding may be of importance in understanding the evolution of coloniality because the outcome of natural selection depends critically on whether a particular behavior is determined genetically or arose from phenotypic plasticity. Although the under- 
lying mechanisms governing resemblance between relatives in social propensity are not clear, it has recently been shown that circulating testosterone predicts breeding colony size and future settlement patterns in cliff swallows, so the existence of variation in degree of sociality could be explained by inherently different neuroendocrinological characteristics (Brown et al. 2005; Smith et al. 2005). Across a range of taxa, there is rapidly accumulating evi. dence not only that within-population variation in behavior reflects phenotypic plasticity or "noise" surrounding adaptive averages but also that individual difference: are consistent over time and are usually domain general, being part of wider behavioral tendencies called syndromes, temperaments, personalities, or coping styles (Wilson 1998; Gosling 2001; Sih et al. 2004). These be havioral syndromes normally have a genetic basis (Van Oers et al. 2005) and are mediated by the neuroendocrine system (Koolhaas et al. 1999). In this context, one possible evolutionary scenario is that natural selection permits the maintenance of variation in social propensity as part of a behavioral syndrome for species in which the relationship between fitness and group size fluctuates in space and/or time as a result of unpredictable changes in predation risk (e.g., Wiklund and Andersson 1994) or in other fitness. related factors. In such species, breeding both solitarily or in colonies of different sizes could be evolutionarily stable strategies explaining the persistence of "transitional states" between territoriality and coloniality (Siegel-Causey and Kharitonov 1990). In others, however, selection pressures could have acted consistently against phenotypes with certain behavioral characteristics, thus triggering the evolutionary jump from territoriality to coloniality. Although this hypothesis provides testable predictions, more research documenting the ubiquity of heritability of group size, its phenotypic and genetic correlation with other behavioral traits, and the underlying physiological basis is needed.

\section{Acknowledgments}

We are grateful to J. A. Donázar, M. G. Forero, A. Gajón, A. Giráldez, J. M. Grande, F. Hiraldo, R. Jovani, R. López, I. Luque, Y. Menor, F. J. Moreno, and E. Ursúa for their help with the fieldwork. We are also grateful to R. Jovani P. Laiolo, R. Montgomerie, F. Sergio, and two anonymous reviewers, whose useful comments contributed to substantially improve the manuscript. During analyzing anc writing, D.S. was supported by a one-year postdoctoral fellowship from the Spanish Ministry of Education and Science and an Itinerario Integrado de Inserción Profesional postdoctoral contract from the Consejo Superior $\mathrm{d} t \rightarrow$ Investigaciones Científicas. Financial support during fieldwork was partially provided by collaborative projects with
Gobierno de Aragón (1994-1995 and 2000), Sociedad Española de Ornitología/BirdLife (1998-1999), and Dirección General de Ciencia y Tecnología and Dirección General de Enseñanza Superior projects PB93-0040 and PB96-0834.

\section{Literature Cited}

Alcaide, M., J. J. Negro, D. Serrano, J. L. Tella, and C. Rodríguez. 2005. Extra-pair paternity in the lesser kestrel: a re-evaluation using microsatellite markers. Ibis 147:608-611.

$\rightarrow$ Andrén, H. 1990. Despotic distribution, unequal reproductive success, and population regulation in the jay Garrulus glandarius L. Ecology 71:1796-1803.

Becker, W. A. 1984. A manual of quantitative genetics. Academic Enterprises, Pullman, WA.

$\rightarrow$ Brown, C. R., and M. B. Brown. 2000. Heritable basis for choice of group size in a colonial bird. Proceedings of the National Academy of Sciences of the USA 97:14825-14830.

. 2001. Avian coloniality: progress and problems. Current Ornithology 16:1-82.

Brown, C. R., and B. Rannala. 1995. Colony choice in birds: models based on temporally invariant site quality. Behavioral Ecology and Sociobiology 36:221-228.

Brown, C. R., B. J. Stutchbury, and P. D. Walsh. 1990. Choice of colony size in birds. Trends in Ecology \& Evolution 5:398-407.

Brown, C. R., M. B. Brown, S. A. Raouf, L. C. Smith, and J. C. Wingfield. 2005. Steroid hormone levels are related to choice of colony size in cliff swallows. Ecology 86:2904-2915.

$\rightarrow$ Brown, J. L. 1969. Territorial behaviour and population regulation: a review and re-evaluation. Wilson Bulletin 81:293-329.

$\rightarrow$ Carrete, M., J. A. Sánchez-Zapata, J. L. Tella, J. M. Gil-Sánchez, and M. Moleón. 2006. Components of breeding performance in two competing species: habitat heterogeneity, individual quality, and density-dependence. Oikos 112:680-690.

$\rightarrow$ Chamberlain, D. E., and R. J. Fuller. 1999. Density-dependent habitat distribution in birds: issues of scale, habitat definition and habitat availability. Journal of Avian Biology 30:427-436.

$\rightarrow$ Clinchy, M., D. T. Haydon, and A. T. Smith. 2002. Pattern does not equal process: what does patch occupancy really tell us about metapopulation dynamics? American Naturalist 159:351-362.

Crawley, M. J. 1993. GLIM for ecologists. Blackwell Scientific, Oxford.

$\rightarrow$ Dittmann, T., and P. H. Becker. 2003. Sex, age, experience and condition as factors affecting arrival date in prospecting common terns, Sterna hirundo. Animal Behaviour 65:981-986.

Donázar, J. A., A. Travaini, O. Ceballos, A. Rodríguez, M. Delibes, and F. Hiraldo. 1999. Effects of sex-associated competitive asymmetries on foraging group structure and despotic distribution in Andean condors. Behavioral Ecology and Sociobiology 45:55-65.

$\rightarrow$ Drent, P. J., K. van Oers, and A. J. van Noordwijk. 2003. Realized heritability of personalities in the great tit (Parus major). Proceedings of the Royal Society B: Biological Sciences 270:45-51.

Ens, B. J., F. J. Welssing, and R. H. Drent. 1995. The despotic distribution and deferred maturity: two sides of the same coin. American Naturalist 146:625-650.

Falconer, D. S., and T. F. C. Mackay. 1996. Introduction to quantitative genetics. Longman, New York.

Ferrer, M., and J. A. Donázar. 1996. Density-dependent fecundity by habitat heterogeneity in an increasing population of Spanish imperial eagles. Ecology 77:69-74. 
$\rightarrow$ Forbes, L. S., and G. W. Kaiser. 1994. Habitat choice in breedin $\rightarrow$ seabirds: when to cross the information barrier? Oikos 70:377384.

Fretwell, S. D. 1972. Populations in a seasonal environment. Princeton University Press, Princeton, NJ.

$\rightarrow$ Fretwell, S. D., and H. L. Lucas. 1970. On territorial behavior and other factors influencing habitat distribution in birds. I. Theoret ical development. Acta Biotheoretica 19:16-36.

$\rightarrow$ Gosling, S. D. 2001. From mice to men: what can we learn abou $\rightarrow$ personality from animal research? Psychological Bulletin 127:4586.

$\rightarrow$ Graves, G. 1997. Geographic clines of age ratios in black-throated blue warblers (Dendroica caerulescens). Ecology 78:2524-2531.

$\rightarrow$ Heg, D., B. J. Ens, H. P. van der Jeugd, and L. W. Bruinzeel. 2000. Local dominance and territorial settlement of nonbreeding oystercatchers. Behaviour 137:473-530.

$\rightarrow$ Holmes, R. T. P. P. Marra, and T. W. Sherry. 1996. Habitat specifi $\rightarrow$ demography of breeding black-throated blue warblers (Dendroica caerulescens): implications for population dynamics. Journal o $\rightarrow$ Animal Ecology 65:183-195.

$\rightarrow$ Kokko, H., M. P. Harris, and S. Wanless. 2004. Competition for breeding sites and site-dependent population regulation in a highl, colonial seabird, the common guillemot Uria aalge. Journal of Animal Ecology 73:367-376.

$\rightarrow$ Komers, P. E. 1989. Dominance relationships between juvenile and adult black-billed magpies. Animal Behaviour 37:256-265.

$\rightarrow$ Koolhaas, J. M., S. M. Korte, S. F. De Boer, B. J. Van Der Vegt, C $\rightarrow$ G. Van Reenen, H. Hopster, I. C. De Jong, M. A. W. Ruis, and H. J. Blokhuis. 1999. Copying styles in animals: current status in behavior and stress physiology. Neuroscience and Biobehaviora $\rightarrow$ Reviews 23:925-935.

Krause, J., and G. D. Ruxton. 2002. Living in groups. Oxford University Press, Oxford.

$\rightarrow$ Lessells, C. M., and P. T. Boag. 1987. Unrepeatable repeatabilities: a common mistake. Auk 104:116-121.

$\rightarrow$ Lima, S. L., and P. A. Zollner. 1996. Towards a behavioural ecology of ecological landscapes. Trends in Ecology \& Evolution 11:131135.

Littell, R. C., G. A. Milliken, W. W. Stroup, and R. D. Wolfinger. 1996. SAS system for mixed models. SAS Institute, Cary, NC.

$\rightarrow$ Maestripieri, D. 2003. Similarities in affiliation and aggression be $\rightarrow$ tween cross-fostered rhesus macaque females and their biological mothers. Developmental Psychobiology 43:321-327.

McCullagh, P., and J. A. Nelder. 1983. Generalised linear modelling $\rightarrow$ Chapman \& Hall, London.

$\rightarrow$ McPeek, M. A., and R. D. Holt. 1992. The evolution of dispersal in spatially and temporally varying environments. American Naturalist 140:1010-1027.

$\rightarrow$ McPeek, M. A., N. L. Rodenhouse, R. T. Holmes, and T. W. Sherry. 2001. A general model of site-dependent population regulation population-level regulation without individual-level interactions. Oikos 94:417-424.

$\rightarrow$ Merilä, J., and B. C. Sheldon. 2000. Lifetime reproductive success and heritability in nature. American Naturalist 155:301-310.

Merilä, J., B. C. Sheldon, and L. E. B. Kruuk. 2001. Explaining stasis microevolutionary studies in natural populations. Genetica 112/ 113:199-222.

$\rightarrow$ Møller, A. P. 1995. Developmental stability and ideal despotic dis $\rightarrow$ tribution of blackbirds in a patchy environment. Oikos 72:228234.
2002. Parent-offspring resemblance in degree of sociality in a passerine bird. Behavioral Ecology and Sociobiology 51:276-281.

Morris, D. W. 2003. Toward and ecological synthesis: a case for habitat selection. Oecologia (Berlin) 136:1-13.

Negro, J. J. 1997. Lesser kestrel Falco naumanni. BWP Update 1:4956.

Newton, I. 1992. Experiments on the limitation of bird numbers by territorial behaviour. Biological Reviews 67:129-173.

Ninni, P., F. de Lope, N. Saino, C. Haussy, and A. P. Møller. 2004. Antioxidants and condition dependence of arrival date in a migratory passerine. Oikos 105:55-64.

O'Connor, R. J. 1985. Behavioural regulation of bird populations: a review of habitat use in relation to migration and residency. Pages 105-142 in R. M. Sibly and R. H. Smith, eds. Behavioral ecology: ecological consequences of adaptive behaviour. Blackwell Scientific, Oxford.

Parker, G. A. 1974. Assessment strategy and the evolution of fighting behaviour. Journal of Theoretical Biology 47:223-243.

Petit, L. J., and D. R. Petit. 1996. Factors governing habitat selection by prothonotary warblers: field tests of the Fretwell-Lucas models. Ecological Monographs 66:367-387.

Post, W. 1992. Dominance and mating success in male boat-tailed grackles. Animal Behaviour 44:917-929.

$\rightarrow$ Postma, E., and A. J. van Noordwijk. 2005. Gene flow maintains a large genetic difference in clutch size at a small spatial scale. Nature 433:65-68.

Poston, J. P. 1997. Dominance, access to colonies, and queues for mating opportunities by male boat-tailed grackles. Behavioral Ecology and Sociobiology 41:89-98.

Potts, G. R., J. C. Coulson, and L. R. Deans. 1980. Population dynamics and breeding success of the shag, Phalacrocorax aristotelis, on the Farne Islands, Northumberland. Journal of Animal Ecology 49:465-484.

Pulliam, H. R., and B. J. Danielson. 1991. Sources, sinks, and habitat selection: a landscape perspective on population dynamics. American Naturalist 137(suppl.):S50-S66.

Rendón, M. A., A. Garrido, J. M. Ramírez, M. Rendón-Martos, and J. A. Amat. 2001. Despotic establishment of breeding colonies of greater flamingos, Phoenicopterus ruber, in southern Spain. Behavioral Ecology and Sociobiology 50:55-60.

Rodenhouse, N. L., T. W. Sherry, and R. T. Holmes. 1997. Sitedependent regulation of population size: a new synthesis. Ecology 78:2025-2042.

Rodenhouse, N. L., T. S. Sillett, P. J. Doran, and R. T. Holmes. 2003. Multiple density-dependence mechanisms regulate a migratory bird population during the breeding season. Proceedings of the Royal Society B: Biological Sciences 270:2105-2110.

Roff, D. A. 1997. Evolutionary quantitative genetics. Chapman \& Hall, New York.

Rohwer, S. 2004. Using age ratios to infer survival and despotic breeding dispersal in hybridizing warblers. Ecology 85:423-431.

Rosenzweig, M. L. 1991. Habitat selection and population interactions: the search for mechanisms. American Naturalist 137(suppl.): S5-S28.

Safran, R. J. 2004. Adaptive site selection rules and variation in group size of barn swallows: individual decisions predict population patterns. American Naturalist 164:121-131.

Schwabl, H. 1996. Environment modifies the testosterone level of a female bird and its eggs. Journal of Experimental Zoology 276: $157-163$. 
Sergio, F., and I. Newton. 2003. Occupancy as a measure of territory quality. Journal of Animal Ecology 72:857-865.

$\rightarrow$ Serrano, D., and J. L. Tella. 2003. Dispersal within a spatially structured population of lesser kestrels: the role of spatial isolation and conspecific attraction. Journal of Animal Ecology 72:400-410.

$\rightarrow$ Serrano, D., J. L. Tella, M. G. Forero, and J. A. Donázar. 2001. Factors affecting breeding dispersal in the facultatively colonial lesser kestrel: individual experience vs. conspecific cues. Journal of AnimaEcology 70:568-578.

$\rightarrow$ Serrano, D., J. L. Tella, J. A. Donázar, and M. Pomarol. 2003. Social and individual features affecting natal dispersal in the colonial lesser kestrel. Ecology 84:3044-3054.

$\rightarrow$ Serrano, D., M. G. Forero, J. A. Donázar, and J. L. Tella. 2004. The role of dispersal and conspecific cues on breeding site selection and colony dynamics of lesser kestrels. Ecology 85:3438-3447.

$\rightarrow$ Serrano, D., D. Oro, E. Ursúa, and J. L. Tella. 2005a. Colony sizc selection determines adult survival and dispersal preferences: Allee effects in a colonial bird. American Naturalist 166:E22-E31.

$\rightarrow$ Serrano, D., J. L. Tella, and E. Ursúa. 2005b. Proximate causes and fitness consequences of hatching failure in lesser kestrels Falcu naumanni. Journal of Avian Biology 36:242-250.

$\rightarrow$ Sherry, T. W., and R. T. Holmes. 1989. Age-specific social dominance affects habitat use by breeding American redstarts (Setophaga ruticillata): a removal experiment. Behavioral Ecology and Sociobiology 25:327-333.

Shields, W. M., J. R. Crook, M. L. Hebblethwaite, and S. S. WilesEhmann. 1988. Ideal free coloniality in the swallows. Pages 189228 in C. N. Slobodchikoff, ed. The ecology of social behavior. Academic Press, San Diego, CA.

Siegel-Causey, D., and S. P. Kharitonov. 1990. The evolution of coloniality. Current Ornithology 7:285-330.

$\rightarrow$ Sih, A., B. Alison, and J. C. Johnson. 2004. Behavioral syndromes: an ecological and evolutionary overview. Trends in Ecology \& Evolution 19:372-378.
Smith, L. C., S. A. Raouf, M. B. Brown, J. C. Wingfield, and C. R. Brown. 2005. Testosterone and group size in cliff swallows: testing the "challenge hypothesis" in a colonial bird. Hormones and Behaviour 47:76-82.

$\rightarrow$ Stirling, D. G., D. Réale, and D. A. Roff. 2002. Selection, structure and the heritability of behaviour. Journal of Evolutionary Biology 15:277-289.

Switzer, P. V. 1993. Site fidelity in predictable and unpredictable habitats. Evolutionary Ecology 7:533-555.

Tella, J. L. 1996. Ecological constraints, costs and benefits of coloniality in the lesser kestrel. PhD diss. University of Barcelona.

Tella, J. L., J. J. Negro, J. A. Donázar, and F. Hiraldo. 1996. Costs and benefits of urban nesting in the lesser kestrel (Falco naumanni). Pages 53-60 in D. M. Bird, D. Varland, and J. J. Negro, eds. Raptors in human landscapes. Academic Press, London.

Tella, J. L., M. G. Forero, F. Hiraldo, and J. A. Donázar. 1998. Conflicts between lesser kestrel conservation and European agricultural policies as identified by habitat use analysis. Conservation Biology 12: 593-604.

Tella, J. L., M. Carrete, J. A. Sánchez-Zapata, D. Serrano, A. Gavrilov, S. Sklyarenko, O. Ceballos, J. A. Donázar, and F. Hiraldo. 2004. Effects of land-uses, nesting-site availability, and the presence of larger raptors on the abundance of breeding lesser kestrels in Kazakhstan. Oryx 38:224-227.

$\rightarrow$ Van Oers, K., G. de Jong, A. J. Van Noordwijk, B. Kempenaers, and P. J. Drent. 2005. Contribution of genetics to the study of avian personalities. Behaviour 142:1191-1212.

$\rightarrow$ Wiklund, C. G., and M. Andersson. 1994. Natural selection of colony size in a passerine bird. Journal of Animal Ecology 63:765-774.

$\rightarrow$ Wilson, D. S. 1998. Adaptive individual differences within single populations. Philosophical Transactions of the Royal Society B: Biological Sciences 353:199-205.

Associate Editor: Robert Montgomerie Editor: Michael C. Whitlock 